\title{
Motivation and Beliefs about the Nature of Scientific Knowledge Within an Immersive Virtual Ecosystems Environment
}

Jason A. Chen

College of William \& Mary, jachen@email.wm.edu

Shari J. Metcalf

Harvard University

M. Shane Tutwiler

Harvard University

Follow this and additional works at: https://scholarworks.wm.edu/articles

Part of the Education Commons

\section{Recommended Citation}

Chen, Jason A.; Metcalf, Shari J.; and Tutwiler, M. Shane, "Motivation and Beliefs about the Nature of Scientific Knowledge Within an Immersive Virtual Ecosystems Environment" (2014). Articles. 14.

https://scholarworks.wm.edu/articles/14

This Article is brought to you for free and open access by W\&M ScholarWorks. It has been accepted for inclusion in Articles by an authorized administrator of W\&M ScholarWorks. For more information, please contact scholarworks@wm.edu. 


\section{Running Head: TECHNOLOGY AND BELIEFS}

Motivation and Beliefs about the Nature of Scientific Knowledge Within an Immersive Virtual

Ecosystems Environment 
TECHNOLOGY AND BELIEFS

\begin{abstract}
We explored Grade 6 students' $(n=202)$ self-efficacy, epistemic beliefs, and science interest over a 10-day virtual ecology curriculum. Pre- and post-surveys were administered, and analyses revealed that (1) students became more self-efficacious about inquiring scientifically after participating in the activity; (2) students on average evinced a shift toward more constructivist views about the role of authority in justifying scientific claims; (3) students who identified more strongly with being a science person evinced greater gains in self-efficacy, developed a less constructivist view about the role of authority in justifying claims, and became more interested in science overall; and (4) students who held an incremental theory of ability evinced greater gains in self-efficacy. We discuss the implications of these findings for science educators and instructional designers in the design and use of immersive virtual worlds for middle school science students.
\end{abstract}

Keywords: Technology; science education; self-efficacy; science identity; epistemic beliefs; implicit theories. 


\section{Motivation and Beliefs about the Nature of Scientific Knowledge Within an Immersive Virtual Ecosystems Environment}

Much research has shown that science is often considered more confusing and more difficult than other academic subjects (Britner, 2007; Cleaves, 2005; Dweck, 2007; National Academies of Science, 2011). Furthermore, in the context of the current educational climate in which such a high premium is put on students' performance on standardized tests, teachers have little time to allow their students to explore science concepts in interesting ways, thereby contributing to students' perception of science as dull. This struggle to motivate students presents a significant challenge especially during the middle school and high school years, when there is a marked general decline in motivation (Eccles, et al., 1983).

In addition to motivating students to do well in science, another major goal of science reform is to advance students' beliefs about the nature of scientific knowledge and knowing (National Academy of Sciences, 2011; National Research Council, 2000, 2007). The more recent work on these beliefs, called epistemic beliefs, has examined relations between the construct and other facets of cognition like motivation and self-regulation (Buehl \& Alexander, 2005; Muis, 2004; Tsai, Ho, Liang, \& Lin, 2011). Less attention, however, has been directed toward how epistemic beliefs change over short periods of time, especially with instructional interventions designed to tap students' epistemic beliefs.

Finally, innovative technologies have been receiving a considerable amount of attention as a way to motivate students, and to provide students with science inquiry experiences that both make learning interesting and provide life-like simulations of what real scientists do. However, despite the widely accepted notion that technology-based activities are inherently motivating, the evidence regarding their motivational effectiveness is mixed (Moos \& Marroquin, 2010). For example, as Moos and Marroquin noted, some research has shown that computer-based 
instruction increased students' interest in the material. But other research has shown that there are a number of variables, such as prior knowledge, that modify the relationship between participation in technology-based activities and students' motivation.

Another reason for these mixed findings could be the way that many researchers exploring educational technologies have conceptualized motivation — as a broad unidimensional construct. However, motivation is multifaceted in that some students may find an activity to be very interesting and enjoyable (i.e., high interest value beliefs) but not consider themselves competent enough to do well (i.e., lack self-efficacy). In fact, even in a recent meta-analysis, Wouters, van Nimwegen, van Oostendorp, \& van der Spek (2013) adopted a broad view of motivation, yet reported findings on the overall construct of motivation without discussing which aspects of motivation seemed to be affected by participation in technology and which aspects did not. Thus, research regarding the motivational affordances of technology should be based firmly in well-studied theories of motivation that treat motivation as a multidimensional construct (Chen, Zap, \& Dede, 2013; Moos \& Marroquin, 2010).

Given the above, three main objectives guided the present study. First, because some have begun to question the truism that technology is inherently motivating, we explored the effect of participating in an inquiry-oriented virtual environment on students' interest in science and their confidence in being able to conduct scientific inquiry to solve a complex problem (i.e., students' self-efficacy for scientific inquiry). Second, because the virtual environment was also designed to tap students' beliefs about the nature of scientific knowledge - their epistemic beliefs - we explored the effect of participating in the virtual environment on students' epistemic beliefs. Third, because numerous variables modify the relationship between participation in technology-rich activities and motivational outcomes, we sought to examine psychological 
moderators of this relationship. In particular, some researchers have shown that certain core assumptions can foster a framework for how students engage with their environment. The first core assumption we investigated was students' theory of ability as either static (fixed theory of ability) or as malleable with effort (incremental theory of ability; Dweck, Chiu, \& Hong, 1995). The second core assumption we studied was students' science identity-beliefs about the extent to which individuals identify with scientists and their work (Estrada et al., 2012; Hernandez et al., 2012; Pugh et al., 2009). In the present investigation we explored whether students' theory of ability and their science identity modified the effect of the intervention on students' selfefficacy, interest, and epistemic beliefs in science.

\section{Theoretical Framework}

\section{Science Self-Efficacy}

Bandura (1997) defined self-efficacy as beliefs in one's capabilities to learn or perform a task at a specified level of competence. Self-efficacy has been shown to affect how productively individuals think, how well they motivate themselves, how long they persist in the face of failures, and ultimately what and how much they achieve (see Pajares \& Urdan, 2006 for a review). In the domain of science, self-efficacy is related to how interested adolescents are in science, the types of goals they set for themselves, their level of achievement, as well as their persistence in pursuing science-related college majors and careers (Andrew, 1998; Beghetto, 2007; Britner \& Pajares, 2001, 2006; Chen \& Pajares, 2010; Gwilliam \& Betz, 2001; Lau \& Roeser, 2002; Lent, Brown, \& Larkin, 1984; Luzzo, Hasper, Albert, Bibby, \& Martinelli, 1999). Given the crucial role self-efficacy has been shown to play, researchers have recently become interested in the various ways that self-efficacy can be formed. Bandura (1997) hypothesized that self-efficacy is formed by how people interpret information from four sources. 
The primary source is how one interprets past performances, or mastery experiences. For example, in science, as students engage in science-related tasks and activities, they interpret how successful they are from these experiences and form conceptions about how capable they are in engaging in subsequent science-related tasks and activities.

Self-efficacy is also influenced by watching the successes and failures of similar others. These vicarious experiences can be especially powerful when the role models whom an individual observes are perceived as being very similar to oneself. Next, teachers, parents, and classmates often send individuals messages, either verbally or through other indirect ways of communicating, about whether they think an individual can succeed. These verbal and social persuasions can be especially influential when they come from sources that an individual trusts. Finally, anxiety, joy, fatigue and other physiological and affective states serve as the fourth and final source of self-efficacy. How students interpret information from this source can often signal to students how competent they are (Bandura, 1997).

Can immersive technologies target these sources to bolster students' self-efficacy? Some researchers have shown that such an endeavor is possible (e.g., Ketelhut, 2007; Moos \& Honkomp, 2011; Hsieh, Cho, Liu, \& Schallert, 2008; Rosenberg-Kima, Baylor, Plant, \& Doerr, 2008). For example, Rosenberg-Kima et al. (2008) used an on-screen avatar that appeared similar and approachable to students to converse with students about the value of engineering careers. This visibly similar avatar was found to be effective at increasing the self-efficacy, interest, and utility beliefs of students in science and engineering courses.

Ketelhut (2007) also showed that students' pre-intervention self-efficacy for scientific inquiry was related to students' initial behaviors within a virtual world. However, after a number of visits to the virtual world, pre-intervention self-efficacy did not appear to affect students' 
behaviors. She hypothesized that one reason why exposure to the virtual world may have nullified the effects of initial self-efficacy is because students were able to take on the identity of a scientist (in the form of an avatar) and possibly benefit from the vicarious experiences of seeing oneself succeed in doing science. This hypothesis represents one promising aspect of immersive technologies - the ability to use virtual role models to convey important information for learners, thereby targeting their vicarious experiences.

\section{Interest}

In addition to beliefs about competence, students can hold beliefs about the value of science. According to Eccles et al. (1983), these beliefs about the value of an activity can have a substantial impact on students' willingness to participate in that activity. Within Eccles et al.'s expectancy-value framework of motivation, we focus specifically on the interest value component because of its germaneness to technology-rich activities. Students' interest value describes the enjoyment that one gains from doing a task. This particular dimension of the expectancy-value framework is relevant for participation in technology-rich activities because technology can spark students' initial interests in participating in an activity (Blumenthal, Kempler, \& Krajcik, 2006). That is, these activities can serve as an initial "hook" for students to continue engaging in a learning task. Numerous studies have also found that interest value is an important factor as students make decisions about choosing careers in Science, Technology, Engineering, and Mathematics (STEM; Lent, Lopez, Lopez, \& Sheu, 2008; Lent, Paixão, Silva, \& Leitão, 2010). Interest value also is related to students choosing to take classes related to STEM fields (Watt et al., 2006).

How might technology-rich activities help support students' evolving interests in science? Some scholars have argued that technology-rich activities can be used to develop 
students' interest in subject matter by making the learning goals relevant and meaningful (Gee, 2003; Squire, 2003). For example, users of a 3-D immersive virtual world called Quest Atlantis assume the role of someone consulting a fictional Council to rebuild an arch that was destroyed by rulers of a fictional world. When learning goals are put within such a context, the learning goals themselves become interesting. Barab, Dodge, Jackson, \& Arici (2003) found that when students completed quests within the Quest Atlantis context they completed significantly more quests and rated them as more interesting compared to those who completed the same exact quests on a worksheet stripped of the fictional story context provided by the virtual world.

In the context of a technology-rich environment, a distinction should be made about the construct interest. Scholars distinguish between situational interest, defined as a short-lived enjoyment in an activity, and individual interest, which describes a long-term investment in an activity (Hidi \& Renninger, 2006). For technology-rich contexts, situational interest can be enhanced by connecting learning goals to personally relevant issues, by varying the challenge of a task, or by providing novel contexts for students to explore.

Although technology can most easily target students' situational interest (e.g., being interested in a virtual science inquiry environment) it is much more difficult to develop that into the more enduring individual interest (e.g., being interested in the field of science). For example, Hickey, Morre, and Pelligrino (2001) found that using the Adventures of Jasper Woodbury videodisc activity alone was not sufficient to promote students' interests in mathematics. Rather, the technology combined with teachers' constructivist instructional practices predicted students' gains in individual interest.

\section{Epistemic Beliefs}


Students also hold beliefs about the nature of scientific knowledge and knowingepistemic beliefs. For example, some students may believe that scientific knowledge is unchanging, and that the best way to accumulate this knowledge is to obtain it from external authorities like teachers or textbooks. Other students might, however, believe that scientific knowledge is continuously in flux, and that anybody can generate this knowledge. Recent work in this area outlines a model that consists of multiple, somewhat independently operating dimensions. That is, individuals can possess highly constructivist beliefs in one dimension (e.g., knowledge is complex and ever-changing) but also possess non-constructivist beliefs in another dimension (scientific knowledge can only be attained from knowledgeable authorities).

Researchers have also shown that these beliefs about knowledge and knowing are related to students' motivation, including their self-efficacy (e.g., Beghetto \& Baxter, 2012; Chen, 2012; Chen \& Pajares, 2010; for a review see Hofer \& Pintrich, 1997). For example, Mason et al. (2013) found that students' beliefs about how scientific knowledge is developed and how it is justified are indirectly related to students' self-efficacy, mediated mostly through the goals that students set for themselves. Chen and Pajares (2010) found that beliefs about the degree to which science is a collection of right or wrong answers were directly related to science selfefficacy. Also, beliefs about how scientific knowledge is appropriately justified were directly related to science self-efficacy.

In Taking Science to School, Duschl et al. (2007) argued that students should participate in science activities that encourage evidence-gathering, proposing explanations for data, forming conclusions by evaluating competing claims, and reconsidering conclusions made from data based on new evidence. Designers of digital science learning activities capable of challenging students' epistemic beliefs need to encourage and support these science inquiry tasks Duschl et 
al. described. Although there are good theoretical and empirical reasons for why inquiry-based learning environments can facilitate the progression of students' epistemic beliefs from less constructivist stances to more constructivist ones, additional research is needed to investigate which aspects of inquiry-oriented environments might be connected to this progression (Bendixen \& Rule, 2004; Feucht \& Bendixen, 2010; Kittleson, 2011; Schraw \& Sinatra, 2004). Because researchers are able to control how aspects of inquiry are presented in technology-based learning environments, such environments may be able to focus on the aspects of inquiry environments that are related to changes in epistemic beliefs. For example, researchers have found that, when students wrestle with conflicting information within complex, open-ended, problem spaces, their epistemic beliefs may evince a development toward more constructivist stances (Barzilai \& Zohar, 2012; Ferguson et al, 2012).

What is less well-known, however, is how these beliefs interact within highly complex immersive virtual worlds, where students do wrestle with complex and open-ended problems, but where the conflicting texts that confront students are less obvious. In the studies presented by those exploring text reading in online contexts, these conflicting elements are presented side-byside. However, in complex immersive virtual worlds designed to simulate real-life problem spaces, such as exploring the causes and effects of a dynamic ecosystem, the conflicting elements are far more subtle. Although inquiry environments that are not technology-rich develop students' inquiry skills and beliefs about the nature of scientific knowledge (cf. Conley, Pinrich, Vekiri, \& Harrison, 2004), technology-enriched environments may further aid in this endeavor by making aspects of scientific phenomena that are difficult to see more obvious.

For example, researchers investigating student understanding of ecosystem dynamics found that students showed promising shifts toward explanations focused on patterns, processes, 
and change over time after using EcoMUVE, a virtual world that supports thinking about change over time and understanding connections between ecosystem factors (Grotzer, et al., 2013). In another study, Metcalf, Kamarainen, et al. (2013) showed that teachers believed EcoMUVE to be more effective than their own traditional science curricula in engaging students and promoting learning of inquiry. Design features of the software that supported students' inquiry activities included the opportunities for student-directed learning, exploration and discovery in the virtual world, ease of collecting and graphing data that showed change over time, and the role-based jigsaw pedagogy. Therefore, immersive virtual worlds that encourage students to collect and view data so that students can more easily understand complex causality potentially have the power to target and develop specific aspects of students' epistemic beliefs. We describe specific aspects of EcoMUVE and how these aspects relate to the constructs we are investigating below.

\section{Implicit Theories of Ability}

Dweck (2002) argued that "much of society is stubbornly wedded to the idea that accomplishment, especially outstanding accomplishment, is about endowment. We ignore the fact that Mozart, Darwin, Michael Jordan, and Tiger Woods practiced feverishly and singlemindedly for years, and instead believe that they were simply born with one-in-a-million ability" (p. 39). This particular belief - that ability is something that people either have or do not havemay be especially prevalent in the context of science classrooms, where students often perceive the subject to be considerably more difficult than their other subjects (National Academies Press, 2011).

According to Dweck (1999), students tend to espouse one of two theories of ability. Some students believe that, with appropriate effort and strategies, they can improve their abilities. Students who hold this incremental theory of ability are more likely to view effort in a 
positive light, persist through difficulties, and ultimately achieve at higher levels than their peers who believe that their abilities cannot be augmented. Students with this latter view-those who hold a fixed theory of ability — are likely to view effort as something that is required to make up for deficits in ability, are more likely to give up in the face of difficulty, and ultimately achieve at lower levels than their incremental theory peers.

Implicit theories of ability can also be domain specific. That is, some students may believe that their science abilities are a relatively stable entity while simultaneously believing that their social studies abilities are increasable (Stipek \& Gralinsky, 1996). As Bandura (1997) observed, "conceptions of ability should not be viewed as monolithic traits that govern the whole of life. The same person may view ability differently in different domains of functioning" ( $p$. 119). Dweck and Leggett (1988) initially showed that implicit theories may apply to areas beyond the intellectual domain, such as in the social domain (i.e., social/personality traits like popularity) and even the moral domain (i.e., moral characteristics such as goodness or badness). Stipek and Gralinski (1996) explored whether implicit theories of ability were domain-specific, and contrary to their original hypothesis, students in Grades 3-6 did not espouse subject-specific beliefs about ability in math and social studies. However, as the researchers posited, "it is possible that, as children enter adolescence and begin to engage in higher level mathematics, their beliefs about ability related to performance in math and other subjects become more differentiated" (p. 403). In fact, Dweck (2002) argued that such differentiation of students' beliefs likely begins in middle school and progresses throughout one's schooling.

Implicit theories of ability have been shown to be core assumptions that color the way students view the world around them (Dweck \& Leggett, 1988; Hong et al., 1999). In the field of science, researchers have found that students who viewed their failures as normal rather than 
as an indication that they did not possess the talent to do well in science exhibited better academic and motivational outcomes (Harsh et al., 2011; Hernandez et al., 2012). Chen and Usher (2013) found that implicit theories of ability modified the ways in which students attended to the sources of self-efficacy. That is, students with an incremental theory of ability were more likely to attend to a variety of adaptive sources of self-efficacy, whereas students with a fixed theory of ability were more likely to attend to negative physiological states as a source of selfefficacy.

The distinction between students with a fixed theory of ability and those with an incremental theory of ability is most salient when students face challenging obstacles (Dweck \& Leggett, 1988). For this reason it is possible that students may navigate an open-ended, inquiryoriented, virtual world in different ways due to the challenging tasks that are presented to students throughout. Students who find it challenging to figure out a scientific problem may report different levels of motivation (e.g., interest and self-efficacy) based on whether they see these challenges as threats (fixed theory of ability) or as opportunities to learn (incremental theory of ability). Although Dweck and her associates have demonstrated this phenomenon within both laboratory and classroom settings, the empirical evidence within virtual contexts does not to our knowledge exist.

\section{Science Identity}

Much like implicit theories of ability, science identity can act as a core assumption that colors the way that students view the world around them. In a broad sense, identity can refer to a sense of who one is ("I am not a science person"). Waterman (2004) defined identity as the goals, values, and beliefs to which people commit. Recent research dealing with identity has shown that science identity can have a significant effect on students' motivation and learning in 
science (Hernandez et al., 2012; Packard \& Nguyen, 2003; Pugh et al., 2009; Roeser, Peck, \& Nasir, 2006). For example, Bergin (1999) has argued that subject-specific identities can have an effect on the development of interests in that particular subject. Pugh et al. also found that students who identified with science also pursued science tasks simply for the sake of learning science, and that this combination of beliefs predicted a deep level of engagement with science.

Finally, immersive virtual environments such as the one utilized in the present study allow students to take on the identity of a scientist. This affordance of immersive technologies can allow students to "willingly suspend their disbelief" (Dede, 2009), and for a moment feel as if they are actually at the pond collecting real data, which EcoMUVE simulates. If students are willing to suspend their disbelief and take on the identity of a scientist, this immersion can translate into a greater interest in science.

\section{Description of the EcoMUVE Curriculum}

We used an immersive virtual world to explore the effects of participating in this technology-rich environment on the above-mentioned beliefs. EcoMUVE is a middle school science curriculum about complex causality in ecosystems in which students learn through inquiry activities in a Multi-User Virtual Environment (MUVE), a 3-D digital world used to simulate complex tasks and processes within an interactive, collaborative, environment. For this study, students used the EcoMUVE Pond module, a two-week curriculum in which students explore a virtual pond ecosystem in order to determine the complex causes of a fish kill in the

pond. Ecosystems are incredibly complex because of the many non-obvious causes and the long time delays between cause and effect. For example, there are many microorganisms that students simply cannot see "at work" in producing causes. Similarly, because ecosystems involve complex processes that take place over long periods of time, the introduction of one 
causal variable may be forgotten by the time its effects are fully noticed by students. EcoMUVE is designed to incorporate virtual tools that help students see the invisible or non-obvious agents within an ecosystem (e.g., microscopic zooplankton). It is also designed to give students virtual abilities that would be impossible in real life (e.g., the ability to travel through time), so that students can more easily see the effects of a process over time.

Students begin EcoMUVE by exploring the pond and its surrounding area by walking their virtual avatar around the 3D environment. They can even walk under the water. A virtual submarine lets them shrink down to view microscopic organisms in the pond. They use a camera tool to photograph the many organisms they find, and learn about them through a virtual field guide. A food web tool lets them learn about the energy relationships between these organisms and the sun. A time travel tool lets them visit the pond on eight different days over a virtual summer. Each day the pond and surrounding area look different, and there are different virtual characters in the world to find and talk to. On one day late in summer they make the surprising discovery that all of the large fish in the pond have mysteriously died. Students are then challenged to figure out the cause of the fish kill, and divided into teams of four to investigate. Each student takes on the role of one of four scientists (e.g., water chemist, microscopic specialist) within the team, and has different tasks and learning quests to complete.

Students use virtual tools to collect data on weather, populations, and water measurements (e.g., temperature, $\mathrm{pH}$, turbidity, etc.). Students can import data from their teammates, and view the data over time using multi-variable graphs. Students also gather clues from their own observations, and by talking to the virtual residents, such as a landscaper putting down fertilizer on the lawns of a nearby housing development. Each team works together to collect and interpret the data, coming up with a hypothesis of the causal factors relating to the 
death of the fish. As the culminating activity, they create a concept map representing their hypothesis and present it to the class.

The collaborative and interactive nature of this environment was designed to engage students' interest in the scientific inquiry task of solving the mystery of the fishkill. EcoMUVE also facilitates student understanding of ecosystem processes by zooming in to the microscopic level, traveling to different points in time, and seeing effects emerge across time and distance. Additionally, EcoMUVE scaffolds the processes of observation and data collection by making it easy to click to retrieve data, by making salient the specific features that are relevant for the investigation, and by organizing data into tables and graphs for analysis. In fact, data suggest that participation in EcoMUVE is indeed linked to students' improvement in ecosystem content understanding (Metcalf, Tutwiler, et al., 2013). Students take on the role of a scientist (through an avatar), and experience data collection and analysis in ways similar to what scientists do. We suggest that, by using the supports that EcoMUVE provides to help students conduct fairly sophisticated scientific inquiry, students are building their self-efficacy (through mastery experiences) by learning how to connect observations to causal ecological processes using data, tables, and graphs that students have generated themselves. Going beyond mere observation by connecting observations to data, and data to specific causal processes in nature is a key element of scientific inquiry. In addition, preliminary data show evidence both of strong student interest in the curriculum (Metcalf, Chen, et al., 2013), and gains in measures such as self-efficacy (Kamarainen et al., 2012).

Finally, we suggest that specific aspects of EcoMUVE tap students' beliefs about the nature of scientific knowledge - their epistemic beliefs. In particular, EcoMUVE's design challenges students to re-think their assumptions regarding where legitimate scientific 
knowledge can originate. For example, when students explore the pond, they meet people who have different types of expertise. A man doing yoga says the pond smells like sewage, a utility worker says she checked the pipes and found no problems, and a golf course manager explains how he's careful using fertilizer. Students have to weigh these claims from the different sources against the data that they have collected and come to a conclusion.

\section{Research Questions and Hypotheses}

Given the objectives of the present study and the theoretical framework outlined above, the following research questions and hypotheses guided us. First, we asked what is the effect of the EcoMUVE curriculum on students' interest in science, and their self-efficacy for scientific inquiry? Based on prior research with EcoMUVE (e.g., Metcalf, Kamarainen et al., 2013; Metcalf, Chen, et al., 2013; Kamarainen et al., 2012), and based on Wouters et al.'s (2013) results indicating that immersive virtual worlds like EcoMUVE can be motivating especially if it is not used in conjunction with traditional forms of teaching, we hypothesized that students' interest in science would increase after participating in EcoMUVE. Because EcoMUVE provides students the opportunity to decide what they will collect and how they will analyze and interpret information, students are provided a great deal of autonomy. Students are also able to do all of this in collaboration with their peers. These inquiry-based aspects of the environment enhance interest in scientific inquiry (Blumenthal, Kempler, \& Krajcik, 2006). These features alone cannot promote students' motivation, however, as students may become frustrated by the complicated features of the inquiry environment. For this reason, EcoMUVE incorporated scaffolds that were designed to support the developing science inquiry skills of students. By supporting students' mastery experiences in scientific inquiry, we hypothesized that students would become more self-efficacious in scientific inquiry after participating in EcoMUVE. 
For our second research question we asked what is the effect of the EcoMUVE curriculum on students' science epistemic beliefs? There is some evidence that interactive learning environments that allow students to design experiments and collect and analyze data may promote epistemic thinking (Solomon, Scott, \& Duveen, 1996). For this reason, we hypothesized that students' epistemic beliefs would evince a shift toward more constructivist stances. That is, students should come to understand that scientific knowledge can originate from themselves and their own reasoning. Students should also learn how to use expert sources (e.g., textbooks or teachers) to decide on the truth of a knowledge claim rather than solely rely on experts to tell them the "correct" answer.

For our third research question we asked to what extent do students' implicit theories of ability and their science identity modify the effect of the intervention on students' self-efficacy, interest, and epistemic beliefs in science? There is some evidence that students' implicit theories of ability form meaning systems that alter the way they process information, including information related to self-efficacy (Chen \& Usher, 2013; Hong, Chiu, Dweck, Lin, \& Wan, 1999; Molden \& Dweck, 2006). For this reason, we hypothesize that students with a fixed theory of ability would evince lower self-efficacy, less interest, and less constructivist epistemic beliefs about science compared to their peers with an incremental theory of ability. We also hypothesized that students who identified less with science would evince lower self-efficacy, less interest, and less constructivist epistemic beliefs about science compared to their peers who identify more with science.

\section{Methods}

\section{Participants}


Participants ( $\mathrm{n}=202)$ were Grade 6 students (11-12 years old) at a relatively affluent and $70 \%$ White suburban school in the Northeastern United States. The student sample included all Grade 6 students at the school; two science teachers each taught five classes of Grade 6 Science, with about 22 students per class. In this particular school, Grade 6 science focuses on life science. Complete pre-post data were received for $94 \%$ of students due to student absences at either the pretest or the posttest, so data for $n=189$ students were analyzed.

\section{Instruments and Procedures}

Pre- and post-surveys were group-administered to students using an online survey (administered via Qualtrics) during science class immediately before and after implementation of the EcoMUVE curriculum. The pre- and post-surveys were comprised of 40 Likert scale questions, and were designed to assess self-efficacy for science inquiry, interest in science,

beliefs about the nature of science, science identity, and implicit theory of ability ${ }^{1}$ (see Appendix A for a list of all items).

Self-efficacy for science inquiry. Students' confidence in being able to perform the tasks involved in scientific inquiry was assessed before and after participation in the EcoMUVE activity using an 8-item instrument $[\alpha=.88(\mathrm{t} 1), .93(\mathrm{t} 2)]$. The tasks identified for scientific inquiry centered on collecting and analyzing data, and making causal inferences using data. Although not an exhaustive list of tasks that comprise scientific inquiry, we chose these particular tasks because they are the central activities of the EcoMUVE curriculum. Students provided ratings on a 6-point scale to indicate their level of confidence in scientifically inquiring about problems. Using MPlus 7.11, we performed a confirmatory factor analysis on the preintervention data to establish the construct validity of this scale. We found that a one-factor model allowing covariance between questions 8 and 6, 7 and 2, and 5 and 1 had acceptable fit 
$\left(\right.$ Model $\left.\chi^{2}(14, \mathrm{~N}=317)=23.457, \mathrm{p}=.06\right)$ with standardized factor loadings ranging from 0.628 to 0.809 and a factor determinacy of 0.949 .

Interest in science. Students' interest and enjoyment for science class and in doing science-related activities was assessed before and after students participated in the EcoMUVE activity by using the interest/enjoyment subscale $[\alpha=.88(\mathrm{t} 1), .90(\mathrm{t} 2)]$ of the Intrinsic Motivation Inventory (IMI; Deci, Eghrari, Patrick, \& Leone, 1994; Ryan, 1982; Ryan, Mims, \& Koestner, 1983). Because we wanted to assess students' subjective experience of interest and enjoyment related to participating in EcoMUVE, this subsection of the Intrinsic Motivation Inventory (IMI) was the only one we used. The IMI has been shown to be valid and reliable (Koka \& Hein, 2003; McAuley, Duncan, \& Tammen, 1987).

Epistemic beliefs. Epistemic beliefs were assessed before and after participating in EcoMUVE along three dimensions of the construct, as outlined by Greene, Torney-Purta, \& Azevedo (2010) with a 13-item instrument. These dimensions include the Simple/Certain Knowledge dimension $[\alpha=.54(\mathrm{t} 1), .45(\mathrm{t} 2)]$, the Personal Justification $[\alpha=.47(\mathrm{t} 1), .43(\mathrm{t} 2)]$ and Justification by Authority $[\alpha=.78(\mathrm{t} 1), .83(\mathrm{t} 2)]$ dimension. Simple/Certain knowledge describes students' beliefs about how static or dynamic scientific knowledge is. Justification of scientific knowledge refers to the degree that individuals believe that personal sources in the form of personal experiences or logic, versus an Authority in the form of an expert, teacher, or another reputable source is sufficient to warrant a knowledge claim. Greene et al. (2010) showed that the instrument was both reliable and valid for the personal justification and the justification by authority dimensions. In their study, however, the simple/certain dimension for mathematics did not appear to be reliable. In our study, we also report low reliability coefficients for the Simple/Certain Knowledge dimension as well as the Personal Justification dimension, which 
would make it difficult for us to make inferences regarding its relation to other constructs in our study. For this reason, we report results only from the Justification by Authority dimension.

Science identity. The degree to which students identify with science and the work that scientists do was assessed before and after students participated in EcoMUVE by using a 4-item instrument $[\alpha=.93(\mathrm{t} 1), .94(\mathrm{t} 2)]$ developed by Pugh et al. (2009). Using a series of exploratory and confirmatory factor analyses, Pugh et al. determined that the science identity construct was distinct from interest value, utility value, self-efficacy, and goal orientations. In the Pugh et al. study, the scale also demonstrated high reliability $(\alpha=.93)$.

Implicit theory of ability. The degree to which students endorsed an incremental view of science ability versus a fixed view of science ability was assessed using a 6-item instrument. This instrument was adapted from one originally developed by Dweck (1999), and consists of six items that ask students specifically about their abilities in science rather than just their general intellectual abilities. Because Stipek and Gralinski (1996) posited that adolescent students may have subject-specific ability beliefs, we modified the wording of Dweck's (1999) original scale so that students focused on their science abilities rather than their abilities in general. The Self form for children 10 years and older (Dweck, 1999) was used and worded to ensure that students focused on their ideas about their own science ability. Three items assessed students' fixed conception of science ability and three others assessed their incremental conception of science ability. For the analysis, we reverse-scored the fixed theory of ability items and calculated a mean theory of ability score with the incremental items. Higher scores represented stronger agreement with incremental theory of ability. When implicit theories of ability have previously been assessed, alpha coefficients have ranged from .77 to .98 (e.g., Blackwell et al., 2007; Chen \& Pajares, 2010; Dweck, Chiu, \& Hong, 1995; Hong et al., 1999; Robins \& Pals, 2002). In the 
present study, alpha coefficients of .83(t1) and .90(t2) for the incremental conception subscale and $.75(\mathrm{t} 1)$ and $.85(\mathrm{t} 2)$ for the fixed conception subscale were obtained. The scale has also been shown to be a valid measure of students' beliefs about the nature of their ability (Dweck, Chiu, \& Hong, 1995).

Although the original scale uses the term "intelligence" and the adapted scale employed in the present study uses the term "science ability" this distinction between intelligence and ability was addressed by Dweck (2002). She stated, "although there are meaningful differences between the terms 'intelligence' and 'ability,' I will use them more or less interchangeably here because the phenomena I am examining most typically apply to both” (p. 58).

\section{Analysis}

Because the present study was nonexperimental, fixed effects regression is a good way to statistically control for variables that were not measured but may have been important (Allison, 2005). Fixed effects methods ignore between-person variations and instead focus on withinperson variations. Even though this method results in somewhat inflated standard errors, this is acceptable for our study because between-person variations are likely contaminated by unmeasured background characteristics of our sample such as previous achievement, facility with technology, or computer gaming experience. Therefore, a fixed effects approach allowed us to derive less biased estimates.

For the first two research questions we wanted to explore changes (if any) in students' self-efficacy for science inquiry, their interest in science, and their epistemic beliefs. We conducted a repeated measures t-test to explore mean changes from time 1 (t1) to time 2 (t2). For the third research question we wanted to explore the extent that students' implicit theories of ability and their science identity modified the effect of EcoMUVE on students' self-efficacy, 
interest, and epistemic beliefs in science. We conducted a fixed effects regression analysis in which self-efficacy, interest, and epistemic beliefs were dependent variables. Time, theory of ability at pre-test, and science identity at pre-test were the independent variables. To control for possible variance in the outcome due to teacher effects, we included a vector of dichotomously coded teacher fixed-effects variables. We included a dichotomously coded variable, "Teacher 1" in our model. Students who were in a classroom taught by that teacher had a value of one, whereas students in classes taught by the other teacher were coded as zero. This, in effect, makes the other teacher a comparison in the vector. We did not directly analyze the results of the coefficient on this variable because it was included only as a statistical control. We chose to control at the teacher level, in lieu of the class level, based on the results of previous studies of EcoMUVE-based interventions, which found little to no intra-class correlation (ICC) at the class level, but moderate to strong ICC at the teacher level (e.g., Metcalf, Tutwiler, Kamarainen, Grotzer, \& Dede, 2013). This can be expressed in the following hypothesized population-level model:

$$
Y_{i j}=\beta_{0}+\beta_{1} T I M E_{i j}+\beta_{2} I N C R_{i j}+\beta_{3} I D E N T_{i j}+\beta_{4} \tau_{j}+\epsilon_{i j}
$$

where $Y_{i j}$ represents one of our dependent variables. We will answer research question 3 by exploring the statistical significance, magnitude, and direction of $\beta_{2}$ and $\beta_{3}$ in models fitted to each outcome.

\section{Results}

Our first two research questions concerned the changes in students' self-efficacy to do science inquiry, their interest in science, and their beliefs about the nature of scientific knowledge and knowing from Time 1 to Time 2. Table 1 shows the means and standard deviations, along with zero-order correlations for Time 1 and Time 2 variables in the study. 
Correlations between Time 1 and Time 2 variables of the same belief (e.g., T1SE and T2SE) ranged from $r=0.57$ to $r=0.82$, suggesting that some beliefs stayed relatively constant (e.g., Interest in science) and some changed (e.g., Self-efficacy).

Table 2 shows the results of a paired samples t-test. After participating in EcoMUVE students, on average, reported greater self-efficacy for inquiring scientifically and evinced a shift toward more constructivist views about the role of authorities in justifying scientific claims. That is, on average, students believed less in the notion that external authorities are the primary source for scientific knowledge. Although not shown in Table 2, there was no significant change in students' theory of ability and no change in students' science identity beliefs from Time 1 to Time 2. We expected that these variables would not change, given that these are assumed to be core assumptions that students held throughout participation in EcoMUVE. One unexpected result was that, on average, there was no significant change in students' interest from Time 1 to Time 2. However, further analysis, described below, revealed a different story.

To address our third research question of examining contextual differences in how students' beliefs changed we performed three fixed effects regressions — one for the justification by authority dimension of epistemic beliefs, and one each for interest in science and selfefficacy. In these analyses, we also included two covariates-science identity and students' theory of ability. Because the covariates are core assumptions, and because we wanted to treat them as exogenous variables to ensure that the covariates are not correlated with the residuals, we used Time 1 identity and theory of ability as covariates rather than the difference between Time 1 and Time 2. Table 3 shows the results from these analyses.

Like the results of the t-test, there was a significant main effect of time for change in selfefficacy showing that students were more self-efficacious after participating in EcoMUVE 
( $\beta=.201 ; p<.05)$, controlling for the level of science identity and belief that science ability can change with effort. We note that, controlling for all other factors, students who reported higher initial science identity scores showed higher gains in self-efficacy $(\beta=.224 ; p<.001)$. Also, students who, at the beginning of EcoMUVE, more strongly believed that their science abilities could grow with effort showed greater gains in self-efficacy $(\beta=.107 ; p<.05)$.

Unlike the results of the t-test, the main effect of time on change in the beliefs about the justification of scientific knowledge by authorities was not significant, controlling for the level of science identity and belief that science ability can change with effort. However, the results also showed that students who more strongly identified with being a scientist at the start of EcoMUVE showed a greater shift toward the belief that scientific knowledge comes mostly from an external authority like a textbook or teacher $(\beta=.089 ; p<.05)$. We offer possible explanations for this counterintuitive finding in the discussion below.

Finally, like the results of the t-tests, there was no main effect of time on change in students' interest in science, controlling for all other covariates in the model. However, the fixed effects regression analysis showed that students who more strongly identified with science reported greater interest in science at the end of EcoMUVE compared to at the start ( $\beta=.489$; $p<.001)$. Theory of ability, however, did not significantly predict change in science interest.

\section{Discussion}

We investigated the effects of participating in an immersive virtual world designed to simulate real-world scientific inquiry on students' motivation and beliefs about the nature of science. Results suggested that participation in EcoMUVE was related to gains in students' selfefficacy for doing scientific inquiry as well as shifts toward more constructivist views about the use of experts' knowledge in justifying scientific claims. However, it appeared that, for those 
who reported stronger identification with science, there was a move toward less constructivist beliefs about the role of authority in producing scientific knowledge. On average, students' interest in science did not change after participating in EcoMUVE. However, students who reported stronger identification with science did evince greater gains in science interest.

\section{How Does EcoMUVE Target Students' Beliefs?}

Self-efficacy. Recall that self-efficacy is formed through mastery experiences, vicarious experiences, social persuasions, and physiological states. EcoMUVE, by providing just-in-time scaffolds and information to students as they explore the virtual pond, allows students to build from initially making observations to being able to draw inferences and test them using data. This targets their mastery experiences. Past research (Ketelhut, Nelson, Clarke, \& Dede, 2010) has shown that students do get better at solving scientific problems systematically, thereby supporting our contention that EcoMUVE may provide students with mastery experiences in scientific inquiry. This is the primary way EcoMUVE supports students' self-efficacy. In addition, the environment is built such that students' affective state does not interfere with their science inquiry, but rather encourages them to consistently engage with science inquiry. For example, there are no time pressures that increase students' anxiety. This and other affectively positive features of the environment, such as the ability to collaborate with peers, support students' self-efficacy through their physiological states.

Self-efficacy caveats. Our results demonstrate that helping students to view science inquiry as a skill that is acquirable may facilitate greater gains in self-efficacy as they participate in an inquiry oriented virtual world. This is in line with Dweck and her colleagues' work showing that implicit theories of ability create a meaning system that influences the ways that students approach learning tasks (Blackwell et al., 2007; Dweck \& Leggett, 1988). As Bandura 
himself stated, "viewing ability as an inherent capacity lowers perceived self-efficacy, retards skill development, and diminishes interest in the activity" (p. 119). Paralleling this statement, we observed that students who believed that their ability to inquire scientifically was a skill that could be augmented with effort also became more self-efficacious. However, students who viewed scientific inquiry as an inborn trait may have become more discouraged when faced with the many challenging tasks that EcoMUVE presented. These results suggest that helping students to understand scientific inquiry as a skill that can be developed may be beneficial to students' self-efficacy.

Our results also demonstrate that students participating in EcoMUVE who already identify with science become more self-efficacious than do their peers who identify less with science. These results are in line with other research suggesting a link between self-efficacy and identity in science (Estrada et al., 2011; Hernandez et al., 2012; Syed, 2010; Syed et al., 2012). Students who identified more strongly with science may have a self-schema or identified a possible self (Markus \& Nurius, 1986) that frames students' actions within the virtual world and allows them to perform the tasks and strategies that are required to successfully navigate the virtual world. In contrast, those who had a weak identification with science may not have had the appropriate interpretive frameworks that such a self-schema provides, and therefore may have been less confident that their actions had been successful. Indeed, Markus and Nurius argued that possible selves, or identities, have consistently been "shown to have a systematic and pervasive influence on how information about the self is processed" (p. 955). And as Syed et al. (2011) posited, students' identities create "prototypes" that help students put into action particular behaviors relevant to that identity that can then build one's sense of efficacy in that domain. For this reason, we believe it is possible that students' greater identification with 
science facilitated students' self-efficacy gains by putting into place the appropriate interpretive frameworks or self-schema that helped students become more self-efficacious in solving complex scientific problems.

Interest. Because students are provided with considerable autonomy in the virtual world (i.e., they can explore any parts of the virtual world they want in whatever sequence they want), EcoMUVE allows students to discover a large variety of interesting objects. Students can also perform a large variety of tests and make observations in collaboration with their peers, enhancing EcoMUVE's ability to engage students' situational interests. In addition, past research has shown that students are, in general, very interested in EcoMUVE and enjoy the experience (Metcalf, Chen, et al., 2013).

Besides targeting students' situational interest, as described above, EcoMUVE was designed to help students see the relevance of doing scientific inquiry by engaging students in a life-like situation in which they engage in the kinds of scientific inquiry tasks that actual scientists do. In fact, in the design process of EcoMUVE a pond ecologist was employed in making the design decisions for the simulation. The expert in pond ecology helped make sure all tasks that students performed closely mirrored what pond ecologists really do. This type of authenticity, combined with the scaffolds to help students understand complex scientific phenomena, was intended to allow students to feel as if they were scientists solving a real environmental problem about a real-life pond. We hypothesized that all these design decisions would develop students' situational interests for EcoMUVE into the more enduring form of individual interest in the process of doing science. This hypothesis was only partially supported, however, as only the individual interests of students who identified with science seemed to develop. We discuss this below. 
Interest caveats. Although there was no main effect of time on students' individual interests in science, there was an interaction with science identity. That is, participants who identified more strongly with being a scientist at the start of EcoMUVE evinced greater gains in science interest than did their peers who did not identify with science. This result supports past research positing that identity plays a crucial role in the development of students' interests within a scholastic domain (Bergin, 1999; Brophy, 1999). In this case, those who more strongly identified with science may have developed a greater interest in science because EcoMUVE not only provides a simulation of a pond ecosystem, but also allows students to perform the types of tasks that scientists really do to solve complex problems (Grotzer et al., 2013). The alignment of students' science identity with the virtual world's simulated representation of what scientists do may have aided in the development of these particular students' interests in science.

However, science educators are concerned not only with students who already see themselves as scientists, but also with those who do not already identify with science. The results of this study provide evidence that using an immersive 3-D virtual world like EcoMUVE alone will not necessarily develop students' interests, especially if these students have a difficult time seeing themselves as scientists. As mentioned earlier, technology may be well positioned to tap students' situational interest, but may not be sufficient to develop it into a more enduring personal commitment to science. In EcoMUVE, it may be that students enjoyed using EcoMUVE, but did not develop that interest into a firmer personal commitment to science in general. As Hickey, Moore, and Pelligrino (2001) showed in their study with The Adventures of Jasper Woodbury, technology-rich activities like EcoMUVE may need to be part of a broader reform-oriented science curriculum if they are to have a more enduring impact on students' individual interest in science. Future research should investigate this possibility by incorporating 
activities like EcoMUVE within a larger teacher-facilitated instructional unit to explore the benefits of the technology within varying forms of constructivist teaching practices.

Epistemic beliefs. Students who identified more strongly with science believed more strongly that scientific knowledge comes mostly from an external authority (considered a less constructivist view). One possible explanation for this counterintuitive finding is that EcoMUVE, although providing an exploratory inquiry-oriented experience for students, also includes many modules and tools that tell students necessary information so that they can solve a problem. For example, students refer to a field manual that tells them information about the plants and animals that they come across. This design decision was made to help students more easily navigate the virtual world. That is, students who are unfamiliar with declarative facts that could be found in a textbook might find it especially frustrating not knowing important pieces of information while trying to solve a complex problem. For this reason, we made available basic information about what they were collecting.

It could be that many students who identified more strongly with science also understood that scientists often must refer to the canon of scientific facts that make up the field of science. Although this portrayal of science is considered "naïve" and less constructivist in the literature on epistemic beliefs, Bråten, Strøms $\varnothing$, and Samuelstuen (2008) argued that whether beliefs are considered naïve or sophisticated must be couched within the context of the activity. For science in particular, it certainly can be adaptive to understand that knowledge provided within EcoMUVE is handed down from an authority like a field guide. There are, however, aspects of scientific knowledge within EcoMUVE that are more tentative and that are open for personal construction and interpretation, as mentioned earlier with the man doing yoga, the utility worker, and the golf course manager. Viewing oneself as a legitimate authority in generating science 
knowledge may be beneficial in that students should consider their own data as legitimate evidence. But students also need to use these three other characters' judgments to come to a conclusion. Therefore, as Bråten and his colleagues have shown, beliefs about justification of knowledge from multiple sources may be an important component in how students interact in complex learning environments like EcoMUVE. This dimension of epistemic beliefs has been shown to be a good predictor of adaptive student outcomes in text comprehension (Ferguson \& Bråten, 2013; Ferguson, Bråten, \& Strømsø, 2012). Future work could investigate the role of this dimension of epistemic beliefs within a complex inquiry-oriented learning environment like EcoMUVE.

\section{Limitations and Delimitations}

In this study we were unable to collect achievement information such as science grades or knowledge of ecology. For this reason we were unable to assess the practical impact of EcoMUVE on students' knowledge or achievement gains. However, past research has shown that participation in EcoMUVE does relate to knowledge gains (e.g., Metcalf, Tutwiler, et al., 2013). What has not yet been addressed, however, and should be further explored in future research, is whether prior achievement or prior knowledge of ecology modifies the relationships that were presented in this study. Some scholars have shown that prior knowledge or achievement can affect how students interact with an inquiry-oriented curriculum (e.g., Chen \& Wu, 2012; Olympiou, Zacharias, \& deJong, 2013; Wang et al., 2010).

The students in this sample were mostly White and middle to high socioeconomic class in the Northeastern US. The students in this sample were also in Grade 6. According to Dweck (2002) students at this particular age are just beginning to see their abilities located within a web of relationships to other variables such as effort and the goals that they pursue (e.g., Dweck, 
2002). It may be that younger students' implicit theories of ability are not as closely tied to their self-efficacy or interests, as Dweck has argued. Therefore, we urge readers to be cautious about applying these results to other samples that differ by demographic features, including age.

Finally, the present study was not experimental —it was correlational by design. Therefore, we cannot assume that the particular designs that were implemented in EcoMUVE lead to particular belief changes among adolescents in science. However, our results do point to some design decisions that may contribute to students' belief changes. Experimental work that manipulates these specific design features is needed to more convincingly establish causality.

\section{Conclusion}

Students may benefit motivationally from innovative technologies that provide both an interactive, life-like, context in which to solve complex scientific problems, and appropriate tools to scaffold students' progression through the learning goals. Such innovative technologies also have the ability to effect changes in the ways that students view the nature of scientific knowledge and knowing. These technologies, however, are not silver bullets - they require the involvement of designers and educators who can implement specific features that target specific educational outcomes. In addition, designers and educators should be aware that, by supporting one type of belief (e.g., self-efficacy), they must also take care not to detract from other beliefs (e.g., communicate the idea that science is nothing more than a canon of truths handed down by an elite few). Instructional designers and science educators who wish to design innovative technologies that develop students' knowledge, skills, and beliefs in science would do well to provide appropriate scaffolds that facilitate students' mastery of increasingly more complicated tasks; allow students opportunities to identify with the work of scientists; and, at the same time, 
challenge students to reconcile multiple perspectives derived from various sources of information. 


\section{References}

Allison, P. D. (2005). Fixed effects regression methods for longitudinal data using SAS®. Cary, NC: SAS Institute.

Andrew, S. (1998). Self-efficacy as a predictor of academic performance in science. Journal of Advanced Nursing, 27, 596-603.

Bandura, A. (1986). Social foundations of thought and action: A social cognitive theory. Englewood Cliffs, NJ: Prentice-Hall.

Bandura, A. (1997). Self-efficacy: The exercise of control. New York: W.H. Freeman.

Barab, S. A., Dodge, T., Jackson, C., \& Arici, A. (2003). Technical report on Quest Atlantis, Volume I. Bloomington, IN: Center for Research on Learning and Technology.

Barzilai, S., \& Zohar, A. (2012). Epistemic thinking in action: evaluating and integrating online sources. Cognition and Instruction, 30, 39-85.

Beghetto, R. A. (2007). Factors associated with middle and secondary students' perceived science competence. Journal of Research in Science Teaching, 44, 800-814.

Beghett, R. A., \& Baxter, J. A. (2012). Exploring student beliefs and understanding in elementary science and mathematics. Journal of Research in Science Teaching, 49, 942960.

Bendixen, L. D., \& Rule, D. C. (2004). An integrative approach to personal epistemology: A guiding model. Educational Psychologist, 39, 69-80.

Bergin, D. A. (1999). Influences on classroom interest. Educational Psychologist, 34, 87-98. 
Blackwell, L. S., Trzesniewski, K. H., \& Dweck, C. S. (2007). Implicit theories of intelligence predict achievement across an adolescent transition: A longitudinal study and an intervention. Child Development, 78, 246-263.

Blumenfeld, P. C., Kempler, T. M., \& Krajcik, J. S. (2006). Motivation and cognitive engagement in learning environments. In Cambridge Handbook of the Learning Sciences (pp. 475-488). Cambridge, U.K.: Bråten Cambridge University Press.

Bråten, I., \& Strømsø, H. I., \& Samuelstuen, M. S. (2008). Are sophisticated students always better? The role of topic-specific personal epistemology in the understanding of multiple expository texts. Contemporary Educational Psychology, 33, 814-840.

Britner, S. L. (2007). Motivation in high school science students: A comparison of gender differences in life, physical, and Earth science classes. Journal of Research in Science Teaching, 45, 955-970.

Britner, S. L., \& Pajares, F. (2001). Self-efficacy beliefs, race, and gender in middle school science. Journal of Women and Minorities in Science and Engineering, 7, 271-285.

Britner, S. L., \& Pajares, F. (2006). Sources of science self-efficacy beliefs of middle school students. Journal for Research in Science Teaching, 43, 485-499.

Brophy, J. (1999). Toward a model of the value aspects of motivation in education: Developing an appreciation for particular learning domains and activities. Educational Psychologist, $34,75-85$.

Buehl, M. M., \& Alexander, P. A. (2005). Motivation and performance differences in students' domain-specific epistemological belief profiles. American Educational Research Journal, 42, 697-726.

Chen, C.H., \& Wu, I. C. (2012). The interplay between cognitive and motivational variables in a 
supportive online learning system for secondary physical education. Computers \& Education, 58, 542-550. DOI: 10.1016/j.compedu.2011.09.012

Chen, J. A. (2012). Implicit theories of ability, epistemic beliefs, and science motivation: A person-centered approach. Learning and Individual Differences, 22, 724-735.

Chen, J. A., \& Pajares, F. (2010). Implicit theories of ability of Grade 6 science students: Relation to epistemological beliefs and academic motivation and achievement in science. Contemporary Educational Psychology, 35, 75-87.

Chen, J. A., Zap, N., \& Dede, C. (2013). Using virtual environments to motivate students to pursue STEM careers: An expectancy-value model. In S. D’Agustino (Ed.), Immersive environments, augmented realities, and virtual worlds: Assessing future trends in education (pp. 42-56). Hershey, PA: IGI Global.

Cleaves, A. (2005). The formation of science choices in secondary school. International Journal of Science Education, 27, 471-486.

Conley, A. M., Pintrich, P. R., Vekiri, I., \& Harrison, D. (2004). Changes in epistemological beliefs in elementary science students. Contemporary Educational Psychology, 29, 186204.

Dede, C. (2009). Immersive interfaces for engagement and learning. Science, 323, 66-69.

Deci, E. L., Eghrari, H., Patrick, B. C., \& Leone, D. (1994). Facilitating internalization: The self-determination theory perspective. Journal of Personality, 62, 119-142.

Duschl, R., Schweingruber, H., \& Shouse, A. (2007). Taking science to school: Learning and teaching science in grades K-8. Washington, D.C.: National Research Council.

Dweck, C. S. (Ed.). (1999). Self-theories: Their role in motivation, personality, and development. Philadelphia: Psychology Press. 
Dweck, C. S. (2007). Is math a gift? Beliefs that put females at risk. In S. J. Ceci \& W. M. Williams (Eds.), Why aren't more women in science? Top researchers debate the evidence (pp. 47-55). Washington, DC: American Psychological Association.

Dweck, C. S., Chiu, C. Y., \& Hong, Y. Y. (1995). Implicit theories and their role in judgments and reactions: A world from two perspectives. Psychological Inquiry, 6, 267-285.

Dweck, C. S., \& Grant, H. (2008). Self-theories, goals, and meaning. In J. Y. Shah \& W. L. Gardner (Eds.) Handbook of motivation science (pp. 405-416). New York: Guilford Press.

Dweck, C. S., \& Leggett, E. L. (1988). A social cognitive approach to motivation and personality. Psychological Review, 95, 256-273.

Eccles, J. S., Midgley, C., \& Adler, T. (1984). Grade-related changes in the school environment: Effects on achievement motivation. In J. Nicholls (Ed.), Advances in motivation and achievement: The development of achievement motivation (Vol. 3, pp. 283-331). Greenwich, CT: JAI Press.

Eccles (Parsons), J. S., Adler, T. F., Futterman, R., Goff, S. B., Kaczala, C. M., Meece, J. L., \& Midgley, C. (1983). Expectancies, values, and academic behaviors. In J. T. Spence (Ed), Achievement and achievement motivation (pp. 75-146). San Francisco: W. H. Freeman.

Estrada, M., Woodcock, A., Hernandez, P. R., \& Schultz, P. W. (2011). Toward a model of social influence that explains minority integration into the scientific community. Journal of Educational Psychology, 103, 206-222.

Feucht, F. C., \& Bendixen, L. D. (2010). Exploring similarities and differences in personal epistemologies of U. S. and German elementary school teachers. Cognition and Instruction, 28, 39-69. 
Ferguson, L. E., \& Bråten, I. (2013). Student profiles of knowledge and epistemic beliefs: Changes and relations to multiple-text comprehension. Learning and Instruction, 25, 4961.

Ferguson, L. E., Bråten, I., \& Strøms $\varnothing$, H. I. (2012). Epistemic cognition when students read multiple documents containing conflicting scientific evidence: A think-aloud study. Learning and Instruction, 22, 103-120.

Gee, J. P. (2003). What video games have to teach us about learning and literacy. New York: Palgrave MacMillan.

Greene, J. A., Torney-Purta, J., Azevedo, R. (2010). Empirical evidence regarding relations among a model of epistemic and ontological cognition, academic performance, and educational level. Journal of Educational Psychology, 102, 234-255.

Grotzer, T.A., Kamarainen, A., Tutwiler, M.S, Metcalf, S, \& Dede, C. (2013) Learning to reason about ecosystems dynamics over time: The challenges of an event-based causal focus. BioScience, 63, 288-296.

Gwilliam, L. R., \& Betz, N. E. (2001). Validity of measures of math- and science-related selfefficacy for African Americans and European Americans. Journal of Career Assessment, 9, 261-281.

Harsh, J. A., Maltese, A. V., and Tai, R. H. (2011). Undergraduate research experiences from a longitudinal perspective. Journal of College Science Teaching, 41, 84-91.

Hernandez, P. R., Schultz, P.W., Estrada, M., Woodcock, A., and Chance, R. C. (in press). Sustaining optimal motivation: A longitudinal analysis of interventions to broaden participation of underrepresented students in STEM. Journal of Educational Psychology. doi: $10.1037 / \mathrm{a} 0029691$. 
Hickey, D. T., Moore, A. L., \& Pellegrino, J. W. (2001). The motivational and academic consequences of elementary mathematics environments: Do constructivist innovations and reforms make a difference?. American Educational Research Journal, 38, 611-652.

Hidi, S., \& Renninger, K. A. (2006). The four-phase model of interest development. Educational Psychologist, 41, 111-127.

Hofer, B. K. (2006). Personal epistemology and culture. In M. S. Khine (Ed.), Knowing, knowledge, and beliefs: Epistemological studies across diverse cultures (pp. 3-22). Berlin: Springer.

Hofer, B. K., \& Pintrich, P. R. (1997). The development of epistemological theories: Beliefs about knowledge and knowing and their relation to learning. Review of Educational Research, 67, 88-140.

Hong, Y. Y., Chiu, C. Y., Dweck, C. S., Lin, D. M. S., \& Wan, W. (1999). Implicit theories, attributions, and coping: A meaning system approach. Journal of Personality and Social Psychology, 77, 588-599.

Hsieh, P. H., Cho. Y., Liu, M., \& Schallert, D. L. (2008). Examining the interplay between middle school students' achievement goals and self-efficacy in a technology-enhanced learning environment. American Secondary Education Journal, 36, 33-50.

Kamarainen, A.M., Metcalf, S., Grotzer, T. \& Dede, C. (2012). EcoMUVE: Shifts in Affective Beliefs and Values About Science Through Learning Experiences in Immersive Virtual Environments. American Educational Research Association (AERA) Conference, Vancouver, BC, Canada. April, 2012. 
Ketelhut, D. J. (2007). The impact of student self-efficacy on scientific inquiry skills: An exploratory investigation in River City, a multi-user virtual environment. Journal of Science Education and Technology, 16, 99-111.

Ketelhut, D. J., Nelson, B. C., Clarke, J. E., \& Dede, C. (2010). A multi-user virtual environment for building and assessing higher order inquiry skills in science. British Journal of Educational Technology, 41, 56-68.

Kittleson, J. M. (2011). Epistemological beliefs of third-grade students in an investigation-rich classroom. Science Education, 95, 1026-1048.

Lau, S., \& Roeser, R. W. (2002). Cognitive abilities and motivational processes in high school students' situational engagement and achievement in science. Educational Assessment, 8, 139-162.

Lent, R. W., Brown, S. D., \& Larkin, K. C. (1984). Relation of self-efficacy expectations to academic achievement and persistence. Journal of Counseling Psychology, 31, 356-362.

Lent, R.W., Lopez, A.M., Lopez, F.G., \& Sheu, H. (2008). Social cognitive career theory and the prediction of interests and choice goals in the computing disciplines. Journal of Vocational Behavior, 73, 52-62.

Lent, R.W., Paixao, M.P., da Silva, J.T., \& Leitao, L.M. (2010). Predicting occupational interests and choice aspirations in Portuguese high school students: A test of social cognitive career theory. Journal of Vocational Behavior, 76, 244-251.

Linnenbrink, E. A., \& Pintrich, P. R. (2002). Motivation as an enabler for academic success. School Psychology Review, 31, 313-327.

Luzzo, D. A., Hasper, P., Albert, K. A., Bibby, M. A., \& Martinelli, E. A., Jr. (1999). Effects of self-efficacy-enhancing interventions on the mathematics/science self-efficacy and career 
interests, goals, and actions of career undecided college students. Journal of Counseling Psychology, 46, 233-243.

Markus, H., \& Nurius, P. (1986). Possible selves. American Psychologist, 41, 954-969.

Mason, L., Boscolo, P., Tornatora, M. C., \& Ronconi, L. (2013). Besides knowledge: A crosssectional study on the relations between epistemic beliefs, achievement goals, selfbeliefs, and achievement in science. Instructional Science, 41, 49-79.

Metcalf, S. J., Kamarainen, A., Tutwiler M. S., Grotzer, T. A. \& Dede, C. J. (2011). Ecosystem science learning via multi-user virtual environments. International Journal of Gaming and Computer-Mediated Simulations. 3(1), 86-90

Metcalf, S. J., Kamarainen, A. M., Grotzer, T., \& Dede, C. J. (2013). Teacher perceptions of the practicality and effectiveness of immersive ecological simulations as classroom curricula. International Journal of Virtual and Personal Learning Environments, 4(3), 66-77.

Metcalf, S. J., Chen, J. A., Kamarainen, A. M., Frumin, K. M., Vickrey, T. L., Grotzer, T. A., Dede, C. J. (2013, April). Shifts in student motivation during usage of a multi-user virtual environment for ecosystem science. Paper presented at the annual meeting of the National Association of Research in Science Teaching (NARST), San Juan, Puerto Rico. Metcalf, S., Tutwiler, M.S., Kamarainen, A., Grotzer, T., \& Dede, C. (2013, April). Multi-user virtual environments to promote middle school ecosystem science learning and attitudes about science. Paper presented at the annual meeting of the American Educational Research Association (AERA) San Francisco, CA.

Moos, D. C., \& Honkomp, B. (2011). Adventure learning: Motivating students in a Minnesota middle school. Journal of Research on Technology in Education, 43, 231-252. 
Moos, D. C., \& Marroquin, E. (2010). Multimedia, hypermedia, and hypertext: Motivation considered and reconsidered. Computers in Human Behavior, 26, 265-276.

Muis, K. R. (2004). Personal epistemology and mathematics: A critical review and synthesis of research. Review of Educational Research, 74, 317-377.

National Academy of Sciences (2011). Expanding underrepresented minority participation: America's science and technology talent at the crossroads. Washington, DC: National Academies Press.

National Research Council. (2000). Inquiry and the national science education standards: A guide for teaching and learning. Washington, DC: National Academy Press.

National Research Council. (2007). Taking science to school: Learning and teaching science in grades $K-8$. Washington, DC: National Academy Press.

Olympiou, G., Zacharias, Z., \& deJong, T. (2013). Making the invisible visible: enhancing students' conceptual understanding by introducing representations of abstract objects in a simulation. Instructional Science, 41, 575-596. DOI: 10.1007/s11251-012-9245-2

Packard, B. W.-L., \& Nguyen, D. (2003). Science Career-Related Possible Selves of Adolescent Girls: A Longitudinal Study. Journal of Career Development, 29, 251-263.

Pajares, F., \& Urdan, T. (Eds.). (2006). Adolescence and education, Vol. 5: Self-efficacy beliefs of adolescents. Greenwich, CT: Information Age Publishing.

Perry, W. G. (1970). Forms of intellectual and ethical development in the college years: A scheme. New York: Holt, Rinehart, and Winston.

Pugh, K. J. (2004). Newton's laws beyond the classroom walls. Science Education, 88, 182196. 
Pugh, K. J., Linnenbrink-Garcia, L., Koskey, K. L. K., Stewart, V. C., \& Manzey, C. (2009). Motivation, learning, and transformative experience: A study of deep engagement in science. Science Education, 94, 1-28.

Robins, R. W., \& Pals, J. L. (2002). Implicit self-theories in the academic domain: Implications for goal orientation, attributions, affect, and self-esteem change. Self and Identity, 1, 313336.

Roeser, R.W., Peck, S.C., Nasir, N.S. (2006). Self and identity processes in school motivation, learning, and achievement. In P. Alexander \& P. H. Winne (Eds.) Handbook of educational psychology (Vol. 2, pp. 391-424). Mahwah, NJ: Lawrence Erlbaum.

Rosenberg-Kima, R. B., Baylor, A. L., Plant, E. A., \& Doerr, C. E. (2008). Interface agents as social models for female students: The effects of agent visual presence and appearance on female students' attitudes and beliefs. Computers in Human Behavior, 24, 2741-2756.

Ryan, R. M. (1982). Control and information in the intrapersonal sphere: An extension of cognitive evaluation theory. Journal of Personality and Social Psychology, 43, 450-461.

Ryan, R. M., Mims, V., \& Koestner, R. (1983). Relation of reward contingency and interpersonal context to intrinsic motivation: A review and test using cognitive evaluation theory. Journal of Personality and Social Psychology, 45, 736-750.

Schraw, G., \& Sinatra, G. M. (2004). Epistemological development and its impact on cognition in academic domains. Contemporary Educational Psychology, 29, 95-102.

Solomon, J., Scott, L., \& Duveen, J. (1996). Large-scale exploration of pupils understanding of the nature of science. Science Education, 80, 493-508.

Squire, K. D. (2003). Video games in education. International Journal of Intelligent Games \& Simulation, 2, 49-62. 
Stipek, D., \& Gralinski, J. H. (1996). Children's beliefs about intelligence and school performance. Journal of Educational Psychology, 88, 397-407.

Syed, M. (2010). Developing an integrated self: Academic and ethnic identities among ethnically-diverse college students. Developmental Psychology, 46, 1590-1604.

Syed, M., Azmitia, M., \& Cooper, C. R. (2011). Identity and academic success among underrepresented ethnic minorities: An interdisciplinary review and integration. Journal of Social Issues, 67, 442-468.

Syed, M., Goza, B. K., Chemers, M. M., \& Zurbriggen, E. L. (2012). Individual differences in preferences for matched-ethnic mentors among high-achieving ethnically diverse adolescents in STEM. Child Development, 83, 896-910.

Tsai, C. C., Ho, H. N., Liang, J. C., \& Lin, H. M. (2011). Scientific epistemic beliefs, conceptions of learning science and self-efficacy of learning science among high school students. Learning and Instruction, 21, 757-769.

Waterman, A. (2004). Finding someone to be: Studies on the role of intrinsic motivation in identity formation. Identity, 4, 209-228.

Wang, J. R., Wang, Y. C., Tai, H. J., \& Chen, W. J. (2010). Investigating the effectiveness of inquiry-based instruction on students with different prior knowledge and reading abilities. International Journal of Science and Mathematics Education, 8, 801-820. DOI: $10.1007 / \mathrm{s} 10763-009-9186-7$

Watt, H. M. G., Eccles, J. S., \& Durik, A. M. (2006). The leaky mathematics pipeline for girls: A motivational analysis of high school enrolments in Australia and the USA. Equal Opportunities International, 25, 642-659. doi:10.1108/02610150610719119 
Zimmerman, B. J. (2000). Attaining self-regulation: A social cognitive perspective. In M.

Boekaerts, P. R. Pintrich, \& M. Zeidner (Eds.), Handbook of self-regulation (pp. 13-39). San Diego: Academic Press. 


\section{Footnote}

${ }^{1}$ We also included four items to assess students' Grit (Duckworth \& Quinn, 2009) because we were interested in students' persistence in the virtual world. However, due to the scale's poor reliability we did not conduct any analyses with this construct. 
Table 1

Zero-Order Correlations of Variables for Time 1 (T1) and Time 2 (T2)

\begin{tabular}{|c|c|c|c|c|c|c|c|c|c|c|c|c|c|}
\hline Variable & $\mathrm{M}$ & $\mathrm{SD}$ & 1 & 2 & 3 & 4 & 5 & 6 & 7 & 8 & 9 & 10 & 11 \\
\hline 1. T1 Self-Efficacy & 4.24 & 0.85 & & & & & & & & & & & \\
\hline 2. T1 Interest & 4.62 & 1.08 & $.428 * * *$ & & & & & & & & & & \\
\hline 3. T1 Fixed & 2.99 & 1.17 & -.095 & -.115 & & & & & & & & & \\
\hline 4. T1 Incremental & 4.58 & 1.03 & $.336^{* * *}$ & $.335^{* * *}$ & $-.503 * * *$ & & & & & & & & \\
\hline 5. T1 Authority & 4.17 & 3.46 & .074 & $.290 * * *$ & .057 & .136 & & & & & & & \\
\hline 6. T1 Identity & 3.46 & 1.46 & $.406^{* * *}$ & $.707 * * *$ & -.142 & $.332 * * *$ & .132 & & & & & & \\
\hline 7. T2 Self-Efficacy & 4.44 & 0.95 & $.567 * * *$ & $.373 * * *$ & -.113 & $.217 * *$ & .063 & $.384 * * *$ & & & & & \\
\hline 8. T2 Interest & 4.61 & 1.11 & $.362 * * *$ & $.816^{* * *}$ & $-.152 *$ & $.263 * * *$ & $.178^{*}$ & $.641 * * *$ & $.556 * * *$ & & & & \\
\hline 9. T2 Fixed & 2.90 & 1.31 & -.121 & -.138 & $.604 * * *$ & $-.516 * * *$ & .051 & $-.183^{*}$ & -.128 & -.134 & & & \\
\hline 10. T2 Incremental & 4.66 & 1.21 & $.274 * * *$ & $.254 * * *$ & $-.447 * * *$ & $.604 * * *$ & .081 & $.220 * *$ & $.363 * * *$ & $.366 * * *$ & $-.533 * * *$ & & \\
\hline 11. T2 Authority & 4.00 & 1.06 & .054 & $.199 * *$ & .142 & .027 & .680 & .079 & $.146^{*}$ & $.204 * *$ & $.169 *$ & .080 & \\
\hline 12. T2 Identity & 3.50 & 1.44 & $.387 * * *$ & $.629 * * *$ & $-.212 * *$ & $.373 * * *$ & .105 & $.827 * * *$ & $.468 * * *$ & $.675 * * *$ & $-.192 * *$ & $.322 * * *$ & $.151 *$ \\
\hline
\end{tabular}

$* p<.05$. ** $p<.01$. *** $p<.001$. 


\section{Table 2}

Table 2

Changes in variables from Time 1 to Time 2

\begin{tabular}{lccc}
\hline \multicolumn{1}{c}{ Variable Name } & $t$ value & $p$ value & Cohen's $d$ \\
\hline Self-Efficacy & 3.23 & 0.0015 & 0.235 \\
Interest & -0.26 & 0.7923 & $\mathrm{n} / \mathrm{a}$ \\
Justification (Authority) & -2.89 & 0.0043 & 0.210 \\
\hline
\end{tabular}

Note. Negative $t$ value for justification by authority represents

a weaker belief in the role of authority as a source of

knowledge. $\mathrm{n} / \mathrm{a}=$ not applicable. 
Table 3

Fixed-Effects Regression With Implicit Theory and Identity as Covariates $(N=186)^{\dagger}$

\begin{tabular}{lllll}
\hline \multicolumn{5}{c}{ Dependent Variable $=$ Justification by Authority } \\
\hline Parameter & Estimate & SE & $\boldsymbol{t}$-value & $\boldsymbol{p}$-value \\
Intercept & 4.078 & 0.25 & 16.13 & $<.0001$ \\
T1 Implicit & -.061 & .057 & -.98 & .232 \\
T1 Identity & .081 & .037 & 2.18 & .030 \\
Time & -.167 & .103 & -1.61 & .108 \\
\hline \multicolumn{5}{c}{ Dependent Variable = Science Interest } \\
\hline Parameter & Estimate & SE & $\boldsymbol{t}$-value & $\boldsymbol{p}$-value \\
Intercept & 2.566 & .205 & 12.52 & $<.0001$ \\
T1 Implicit & .078 & .046 & 1.55 & 0.122 \\
T1 Identity & .489 & .030 & 15.82 & $<.0001$ \\
Time & -.011 & .084 & -.14 & 0.888 \\
\hline \multicolumn{1}{c}{ Dependent Variable $=$ Self-Efficacy for Scientific Inquiry } \\
\hline Parameter & Estimate & SE & $\boldsymbol{t}$-value & $\boldsymbol{p}$-value \\
Intercept & 3.018 & .210 & 14.35 & $<.0001$ \\
T1 Implicit & .109 & .047 & 2.32 & .021 \\
T1 Identity & .228 & .031 & 7.34 & $<.0001$ \\
Time & .201 & .086 & 2.34 & .020 \\
\hline
\end{tabular}

+ Models control for teacher fixed-effects 


\section{APPENDIX A}

\section{Scales and Knowledge Assessment Items}

Participants responded to all self-report items on a 6-point Likert scale from 1 (Completely False or Not at all confident) to 6 (Completely true or Completely confident).

\section{Self-Efficacy for Science Inquiry:}

1. How confident are you that you can do the following things:

a. Figure out the reasons why things happen in nature

b. Use tables and graphs to figure things out.

c. Figure out the relationships between organisms and environments.

d. Look at data that I collect and see how it fits together.

e. Connect the things that I am learning about in science with what I already know.

f. Figure out what causes changes in an environment.

2. How confident are you that you can ...

a. Do the kinds of things that scientists do.

b. Solve the kinds of complicated problems that scientists have to solve.

\section{Science Interest}

1. I find science enjoyable

2. Science is just not interesting to me (reverse scored)

3. I like doing work in my science class

4. I like learning new things in science

5. In general, I find working on science assignments to be interesting

\section{Epistemic Beliefs (Justification by Authority)}

1. If a scientist says something is a fact, I believe it

2. Things written in a science textbook are true

3. I believe everything I learn in science class

4. If a science teacher says something is a fact, I believe it

\section{Epistemic Beliefs (Personal Justification)}

1. Scientific knowledge is all factual and there are no opinions

2. In science, everyone's knowledge can be different because there is no absolutely right answer

3. In science, if you believe something is a fact, no one can prove to you that you are wrong

4. In science, what's a fact depends on a person's point of view

\section{Epistemic Beliefs (Simple and Certain Knowledge}

1. In science, the truth means different things to different people

2. To know science well, you need to memorize what you are taught

3. In science, what is a fact today will be a fact tomorrow

4. Scientists' knowledge of the facts about science does not change

5. Science is so complex that humans will never really understand it 


\section{Conceptions of Ability (Incremental)}

1. No matter who you are, you can change your science abilities a lot

2. No matter how much science ability you have, you can always change it quite a bit

3. You can always change how much science ability you have.

\section{Conceptions of Ability (Fixed)}

1. You have a certain amount of science ability, and you really can't do much to change it

2. Your science ability is something about you that you can't change very much

3. You can learn new things in science, but you can't really change your basic science ability

\section{Science Identity}

1. Being involved in science is a key part of who I am

2. I can see science-related activities as being a part of my future

3. I consider myself a science person

4. I can see myself being involved in a science-related career

\section{Knowledge of Ecosystems}

1.) Which of the following words describes the most basic unit of matter?
a. cells
b. atoms
c. molecules
d. compounds

2.) Use the food chain below to answer the question.

$$
\text { grass } \rightarrow \text { caterpillar } \rightarrow \text { bird } \rightarrow \text { snake } \rightarrow \text { hawk }
$$

Which of the following living things is the producer in the food chain?
a. grass
b. caterpillar
c. bird
d. hawk

3.) What causes a high chlorophyll measurement in pond water?
a. an increase in the amount of algae
b. a decrease in the amount of bacteria
c. the introduction of an invasive fish species
d. rainwater runoff from a nearby construction site

4.) Which of the following words describes the condition when pond water is cloudy and hard to see through?
a. chlorophyll
b. nitrates
c. $\mathrm{pH}$
d. turbidity 
5.) Which is the best $\mathrm{pH}$ range for water organisms to be healthy?
a. $1-2$
b. $2-4$
c. $4-6$
d. $6-8$

6.) What is the origin (or primary source) of the energy that is stored in food?
a. air
b. plants
c. soil
d. sunlight

7.) How do decomposers obtain their food?
a. by consuming living plant materials
b. by hunting and killing other organisms
c. by absorbing food from dead organisms
d. by producing food from oxygen and sunlight

8.) What is the name of the process that uses oxygen to break apart sugars for energy?
a. circulation
b. digestion
c. photosynthesis
d. respiration

9.) What is most likely to happen next if you add nitrates and phosphates to water for plants?
a. the plants die
b. the plants get smaller
c. the plants get bigger
d. there is no effect on the plants

10.) Which are produced during photosynthesis?
a. carbon dioxide and minerals
b. carbon dioxide and sugar
c. oxygen and minerals
d. oxygen and sugar 